\title{
Investigation on energy absorption efficiency of each layer in ballistic armour panel for applications in hybrid design
}

DOI:

10.1016/j.compstruct.2016.12.057

\section{Document Version}

Accepted author manuscript

Link to publication record in Manchester Research Explorer

\section{Citation for published version (APA):}

Yang, Y., \& Chen, X. (2017). Investigation on energy absorption efficiency of each layer in ballistic armour panel for applications in hybrid design. Composite Structures, 164. https://doi.org/10.1016/j.compstruct.2016.12.057

\section{Published in:}

Composite Structures

\section{Citing this paper}

Please note that where the full-text provided on Manchester Research Explorer is the Author Accepted Manuscript or Proof version this may differ from the final Published version. If citing, it is advised that you check and use the publisher's definitive version.

\section{General rights}

Copyright and moral rights for the publications made accessible in the Research Explorer are retained by the authors and/or other copyright owners and it is a condition of accessing publications that users recognise and abide by the legal requirements associated with these rights.

\section{Takedown policy}

If you believe that this document breaches copyright please refer to the University of Manchester's Takedown Procedures [http://man.ac.uk/04Y6Bo] or contact uml.scholarlycommunications@manchester.ac.uk providing relevant details, so we can investigate your claim.

\section{OPEN ACCESS}




\section{Accepted Manuscript}

Investigationonenergyabsorptionefficiencyofeachlayerinballistic armour panel forapplications in hybriddesign

Yanfei Yang, Xiaogang Chen

PII:

S0263-8223(16)32030-X

DOI: http://dx.doi.org/10.1016/j.compstruct.2016.12.057

Reference: COST 8112

To appear in:

\section{Composite Structures}

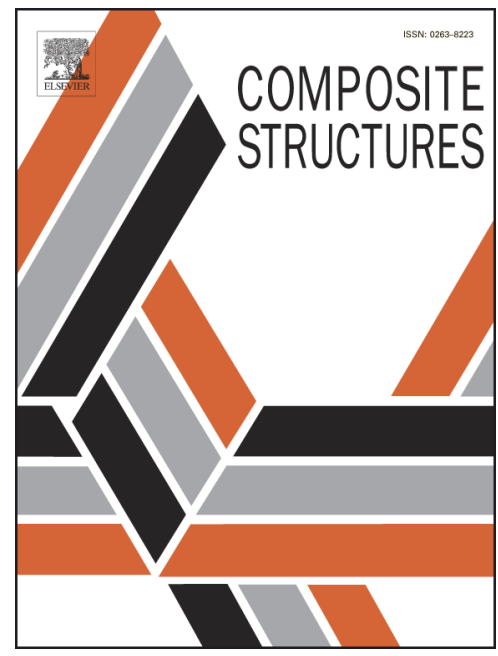

Received Date: $\quad 30$ September 2016

Revised Date: 8 December 2016

Accepted Date: $\quad 15$ December 2016

Please cite this article as: Yang, Y., Chen, X., Investigationonenergyabsorptionefficiencyofeachlayerinballistic armour panel forapplications in hybriddesign, Composite Structures (2016), doi: http://dx.doi.org/10.1016/ j.compstruct.2016.12.057

This is a PDF file of an unedited manuscript that has been accepted for publication. As a service to our customers we are providing this early version of the manuscript. The manuscript will undergo copyediting, typesetting, and review of the resulting proof before it is published in its final form. Please note that during the production process errors may be discovered which could affect the content, and all legal disclaimers that apply to the journal pertain. 


\title{
Investigation on energy absorption efficiency of each layer in ballistic armour panel for applications in hybrid design
}

\author{
Yanfei Yang ${ }^{1,2,3}$, Xiaogang Chen ${ }^{2}$ \\ 1. School of Textile, Zhongyuan University of Technology, Zhengzhou, Henan, China \\ 2. School of Materials, University of Manchester, Manchester, UK \\ 3. Henan Collaborative \& Innovation Centre
}

(Corresponding author email: yyf@zut.edu.cn)

Corresponding author: Yanfei Yang, School of Textile, Zhongyuan University of

Technology, 41 Zhongyuan Road, Zhengzhou, China, 450007, Tel: 0086-18236906176,

Email: yyf@zut.edu.cn 


\title{
Investigation of energy absorption efficiency of each layer in ballistic armour panel for applications in hybrid design
}

\begin{abstract}
This study aims to reveal different energy absorption efficiency of each layer when armour panel is under ballistic impact. Through Finite Element (FE) modelling and ballistic tests, it is found that when fabrics are layered up in a panel, energy absorption efficiency is only $30 \%$ $60 \%$ of an individual fabric layer with free boundary condition. In addition, fabric layers in front, middle, and back exhibit different ballistic characteristics. Therefore, a new hybrid design principle has been proposed. A multilayer panel can be divided into three groups. Two hybrid panels that are combined different Twaron fabrics and Dyneema UD laminates are designed. Ballistic tests results show that for a given areal density of the panel, BFS behind the hybrid panel decreases $31.54 \%$ than that of the woven fabric panel. When the areal density of armour panel is reduced, the hybrid panel is more likely to stop the projectile. These findings provide a guide for hybrid design of ballistic armour panel.
\end{abstract}

\section{Keywords:}

Ballistic armour panel, Finite Element (FE), ballistic test, energy absorption efficiency, hybrid design. 


\section{Introduction}

Ballistic body armour made from high performance fibres, such as aramid, and Ultra High Molecular Weight Polyethylene (UHMWPE) fibres, is widely used in personnel ballistic protective clothing for military and law enforcement application, due to typical flexibility, and light-weight [1-3]. Traditionally, an armour panel is manufactured by layering numerous woven fabric layers with weight of 3 to $5 \mathrm{Kg}$ [1]. However, according to previous studies, each fabric layers at different positions of a multilayer panel plays different roles in ballistic resistance [4] [5] [6] [7] [8].

Joo and Kang [4] used FE model to analyse energy absorption of each layer in multilayer panels. He concluded that in the non-perforation case, the absorbed energy is the highest for the first layer followed by the subsequent layers. When the perforation occurs, the sequence is reversed. Cunniff [6] reported that material near the striking face has little influence on ballistic performance of an armour panel when the impact velocity is much higher than the ballistic limit. Chen [5] [9] explained that the front layers of fabric in a multilayer panel are more likely to be broken in shear, and the back layers of fabric tend to fail in tension. As a result, energy absorption of each layer is increased from front to back in the panel. In our previous studies [10-12], it was found that when a multilayer panel is under ballistic impact, energy absorption of each layer is increased from the front layer to the peak value at the last perforated layer and then gradually decreased in following back layers of the panel. Such pattern has not been influenced by the total number of layers in the panel. When increasing the threat level, only the position of the peak value of energy absorption with the last perforated layer is shifted towards back of the panel.

Due to different roles of each layer in ballistic resistance, layering up same fabrics in a panel cannot be the most efficient method for ballistic performance. In recent years, many 
patents and commercial hybrid products have been proved to be very efficient in providing superior ballistic performances and reductions in weight [13-16]. The Honeywell Company [15] designed 21-layers hybrid armour panel with a sandwich structure by combining Spectra Shields ${ }^{\circledR}$, Gold Flex ${ }^{\circledR}$, and Kevlar ${ }^{\circledR}$. It possesses lighter weight, a greater range of threat protection, and improved comfort, flexibility. The desired ballistic performance can be achieved by manipulating the order of layering up and the number of layers. Karahan [16] observed that hybrid panels combining para-aramid woven fabrics and K-Flex ${ }^{\circledR}$ UD laminate can achieve around $4.5 \%$ reduction in BFS and $8.5 \%$ improvement in energy absorption per unit weight compared to $100 \%$ woven fabric panels. In Chabba's patent [13], a multi-layered panel combines sub-stacks of trauma reducing layers and fibrous layers. The decreasing BFS of the hybrid panel can reach $9.52 \%$ compared to the Dyneema ${ }^{\circledR}$ UD panel. Although the positive hybrid effect on ballistic performance of the multi-layer system has already been demonstrated, most of these studies only focused on the layering up effect of hybridisation. A general design principle for hybrid armour panel has not been identified.

In addition, mechanisms responding to the hybridisation effect have never been fully understood. Cunniff [17] experimentally studied the effect of layering sequence of a two-layer system combining Kevlar ${ }^{\circledR}$ (low modulus) and Spectra $^{\circledR}$ (high modulus) woven fabrics. Ballistic performance of V50 shows differences between these two hybrid panels with reverse layering sequence. He explained that different modulus of materials can result in the interference of transverse deflection under ballistic impact. This leads to reduction of energy absorption in a panel when a material with high modulus was placed before a material with low modulus. Above test results have been investigated by Porwal and Phoenix [18] through a theoretical and numerical model. It was found that the interference between two layers had a significant influence on strain evolution in layers, in particularly near the edge of the projectile where failure initiates. Park et.al [19] concluded the hybridization effect is 
determined by the modulus of materials. He found that the hybrid panel with components in the order of decreasing modulus enhanced the penetration resistance. The layering up sequence of components with the increasing modulus is beneficial to reduce BFS. In Rahman's study, FE results showed that the contact force of woven panel was higher than that of rigid laminate panel. This results in more energy absorption in the woven panel [20]. Although a considerable work on ballistic responses of multilayer panel has been done, the different contribution of each layer in ballistic resistance still need to be further investigated. Such understanding is important for the construction optimising of ballistic armour panel.

Our previous studies focus on identifying a general energy absorption distribution in a multilayer armour panel at different ballistic impact conditions $[10,11]$. This study aims to further quantify energy absorption efficiency of each layer, and propose a new hybrid design principle. Finite Element (FE) simulation and ballistic tests are used to explore different ballistic characteristics of fabric layers at different positions in a panel. Hybrid panels are designed and conducted ballistic tests to confirm the positive effect of this hybrid design principle in improvement of ballistic performance and weight reduction.

\section{Numerical modelling}

In this research, three-dimensional (3D) FE models of armour panels under transverse impact of a projectile were created using ABAQUS/Explicit. FE modelling of non-perforated armour panels under transverse impact is referred to the model in our previous study [10]. In order to quantify energy absorption efficiency of each fabric layer in a multilayer panel, an FE model of an individual layer of fabric panel, namely $11 \mathrm{~F}$, is also developed. It represents full energy absorption capacity of Twaron fabric at free boundary condition under ballistic impact, which is a baseline for energy absorption efficiency. Due to the structural symmetry, only onequarter of FE system is modelled. 
A steel Right Circular Cylinder (RCC) projectile is used to impact armour panels, which has the diameter and height of $5.5 \mathrm{~mm}$, and $1 \mathrm{~g}$ in mass. The impact velocity of the projectile is $483 \mathrm{~m} / \mathrm{s}$. Twaron ${ }^{\circledR}$ plain fabrics $11 \mathrm{~F}$ are used to construct armour panels. The specifications of this fabric are listed in Table 1.

Table 1 Specifications of materials

\begin{tabular}{|c|c|c|c|c|c|c|c|}
\hline \multirow{2}{*}{ Material } & \multirow{2}{*}{ Code } & \multicolumn{2}{|c|}{$\begin{array}{l}\text { Yarn count } \\
\quad(\text { tex })\end{array}$} & \multicolumn{2}{|c|}{$\begin{array}{l}\text { Yarn density } \\
\text { (ends/cm) }\end{array}$} & \multirow{2}{*}{\multicolumn{2}{|c|}{$\begin{array}{c}\text { Thickness Areal density } \\
(\mathrm{mm}) \quad\left(\mathrm{g} / \mathrm{m}^{2}\right)\end{array}$}} \\
\hline & & Warp & Weft & Warp & Weft & & \\
\hline \multirow{2}{*}{$\begin{array}{l}\text { Twaron } \\
\text { fabric }\end{array}$} & $11 \mathrm{~F}$ & 93 & 93 & 11 & 11 & 0.26 & 196.85 \\
\hline & $13 \mathrm{~F}$ & 93 & 93 & 13 & 13 & 0.32 & 251.76 \\
\hline $\begin{array}{c}\text { Dyneema } \\
\text { UD }\end{array}$ & $\mathrm{U}$ & / & / & I & 1 & 0.24 & 186.94 \\
\hline
\end{tabular}

In an armour panel, fabric layers are modelled at the yarn level. A single yarn is represented as a three-dimension (3D) solid body with a lenticular cross-section and defined crimp wave in FE model, as shown in Figure 1(a). According to the fabric thickness $(0.26$ $\mathrm{mm})$ and the weave density of the fabric $(10.9 \mathrm{ends} / \mathrm{cm})$, the width of the yarn cross-section and the length of the crimp wave can be calculated as $0.0881 \mathrm{~cm}$ and $0.1832 \mathrm{~cm}$ respectively. The same yarns are assembled in warp and weft directions to construct a single layer of plain fabric with the size of $75 \times 75 \mathrm{~mm}$. The FE model of an individual fabric panel under impact is shown in Figure 1(c).

In a non-perforation case, three FE models of multilayer panels with 24, 36 and 48 layers which can stop the projectile were created, namely $11 \mathrm{~F}_{24}, 11 \mathrm{~F}_{36}$ and $11 \mathrm{~F}_{48}$. A multilayer panel is created by overlapping a certain number of fabric layers. According to NIJ standard-0101.06 [21], Roma Plastilina No.1 oil based modelling clay is used as backing material to record the configuration of the indentation after impact. It is modelled as a 3D 
solid continuum block with the size of $75 \times 75 \times 50 \mathrm{~mm}$. FE model of a multilayer panel under impact is shown in Figure 1 (d).

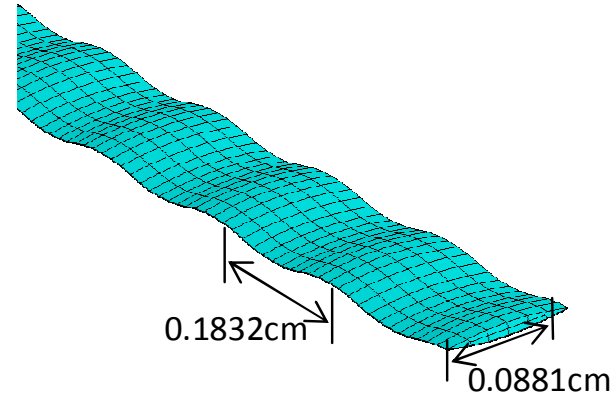

(a)

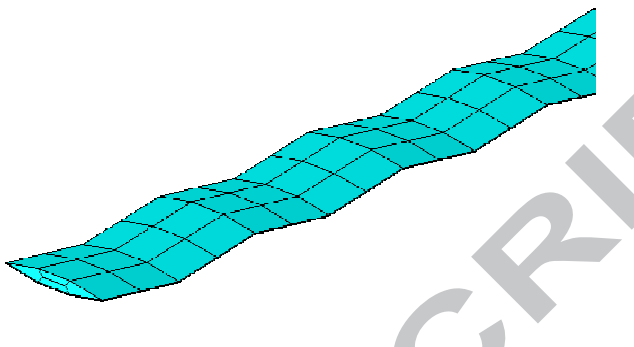

(b)

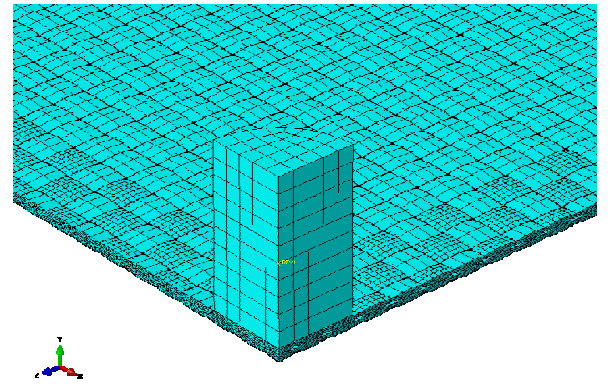

(c)

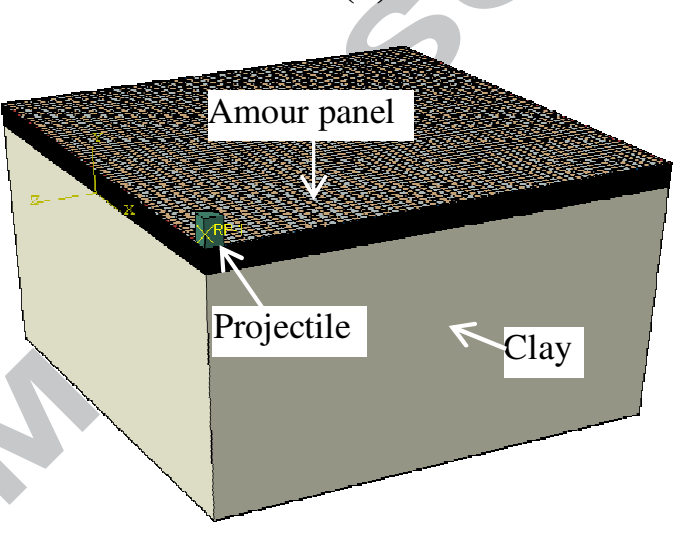

(d)

Figure 1 FE modelling (a) fine mesh in a primary yarn; (b) coarse mesh in a secondary yarn; (c) FE model of a single fabric layer under impact; (d) FE model of a multilayer panel before clay under impact [10]

For the non-perforated panels, free boundary conditions are assigned for the outer edges of the panel. The other two edges crossing at the impact area are applied symmetry conditions. The clay is placed inside a container. Therefore, the constraint boundary conditions are assigned for the outer edges and the back of the clay. The symmetry conditions are applied for the other two edges crossing at the impact area. For the FE model of an individual layer of fabric under impact, the back clay is removed. A free boundary condition is applied for the individual layer.

In order to reduce the number of elements and ensure the accuracy of calculation, fine mesh size and coarse mesh size are used for primary yarns and secondary yarns respectively. 
For the clay model, a transition mesh sizes are adopted. Eight node hexahedron elements (C3D8R) were used for yarns, projectile and clay in the model. The general contact algorithm and simple coulomb friction is used for all contact surfaces in the FE model. The friction coefficient is assumed to be 0.2 according to Rao's tests results [22]. The impact velocity of $483 \mathrm{~m} / \mathrm{s}$ is assigned to the projectile perpendicular to the armour plane.

Assignment of material properties for FE model is also referred to our previous study [10]. The yarn model and clay are assumed to be homogeneous and isotropic material. Material properties of Twaron yarns are obtained from product properties of Teijin ${ }^{\circledR}$ Company. Material properties of clay are referred to test results of Pamukcu's study [23]. Material behaviour of yarns and clay under impact are both defined as linear elastic-plastic. Ductile damage of yarn is assumed and applied in the model. The damage evolution law of yarn model is specified in terms of the fracture energy. Material softening is defined as exponential form. Due to no obvious deformation produced in ballistic tests, the steel projectile is modelled as a rigid body. Material properties of FE model are listed in Table 2.

Table 2 Material properties of FE model [10]

\begin{tabular}{llcc}
\hline Material properties & Projectile & Twaron & Clay[23] \\
\hline Yield stress (GPa) & Rigid body & 3.6 & $6 \times 10^{-5}$ \\
Fracture strain (\%) & Rigid body & 4.0 & $/$ \\
Young's Modulus(GPa) & 206.8 & 90 & $6.58 \times 10^{-3}$ \\
Poisson's ratio & 0.3 & 0.35 & 0.496 \\
Mass Density $\left(\mathrm{kg} / \mathrm{m}^{3}\right)$ & 7800 & 1440 & 1539 \\
Angle of internal friction $\left(^{\circ}\right)$ & $/$ & $/$ & 61 \\
Flow stress ratio & $/$ & $/$ & 1.0 \\
Dilation angle $\left({ }^{\circ}\right)$ & $/$ & $/$ & 0 \\
\hline
\end{tabular}

\section{Ballistic test}


In order to validate FE model and hybrid design principle, ballistic tests were conducted at the ballistic laboratory in the University of Manchester. Two types of Twaron woven fabric, namely $11 \mathrm{~F}$ and $13 \mathrm{~F}$, with the same yarns of 93tex and different weave densities are produced in the weaving lab of University of Manchester. Dyneema UD laminates (SB71) are also adopted as a component for hybrid panels, which is denoted by U. The specifications of these materials are listed in Table 1.

A series of panel samples were prepared for ballistic tests to identify ballistic performance, including Twaron fabric panels and two designed hybrid panels, as shown in Table 3. For Twaron fabric panels, the subscript represents the total number of layers. For hybrid panels, each component was listed in the layering sequence which is from the striking face to the exiting face and separated by the ' $/$ '. The subscript represents the number of layers of one component.

Table 3 Specimen of armour panels

\begin{tabular}{cccc}
\hline Material & Sample & $\begin{array}{c}\text { The number of } \\
\text { layer }\end{array}$ & $\begin{array}{c}\text { Areal density } \\
\left(\mathrm{g} \mathrm{m}^{-2}\right)\end{array}$ \\
\hline & $11 \mathrm{~F}$ & 1 & 196.85 \\
\hline $\begin{array}{c}\text { Twaron } \\
\text { fabric } \\
\text { panel }\end{array}$ & $11 \mathrm{~F}_{15}$ & 15 & 2952.75 \\
& $11 \mathrm{~F}_{24}$ & 24 & 4724.40 \\
& $11 \mathrm{~F}_{36}$ & 36 & 7086.60 \\
\hline $\begin{array}{c}\text { Hybrid } \\
\text { panel }\end{array}$ & $11 \mathrm{~F}_{48}$ & 48 & 9448.80 \\
\hline & $13 \mathrm{~F}_{3} / 11 \mathrm{~F}_{7} / \mathrm{U}_{14}$ & 24 & 4750.39 \\
\hline
\end{tabular}

The steel RCC projectile $(5.5 \mathrm{~mm}$ in diameter and height, $1.004( \pm 0.008) \mathrm{g}$ in weight $)$ for impact is fired by a machine simulating hand gun and propelled by gunpowder. The 
impact velocities are in the range of $460 \sim 500 \mathrm{~m} / \mathrm{s}$. The average striking velocity on fabric was calculated as $483 \mathrm{~m} / \mathrm{s}$, which is the velocity of the projectile contacting the panel. A firing range used for impact tests was shown in Figure 2 (a).

For the multilayer panel, the non-perforation tests were conducted. A panel sample was placed before clay box with two elastic tapes fixed, as shown in Figure 2 (b). The clay is put into the oven at $38^{\circ} \mathrm{C}$ above 3 hours before ballistic test according to the NIJ standard. After impact, an indentation was remained in the clay. Back-face Signature (BFS) is used to assess ballistic performance of the non-perforated armour panels. BFS is the perpendicular distance from the reference plane of the clay surface to the deepest point of indentation. It can be directly measured by a vertical calliper, as shown in Figure 2 (c). Due to stable test results of BFS, ballistic tests are repeated by five shots.

An individual fabric were conducted the perforation test. The clay is removed. A layer of fabric with the size of $240 \mathrm{~mm} \times 240 \mathrm{~mm}$ was placed before a square steel frame with two elastic tapes fixed to keep free boundary condition. Ballistic performance of the perforated fabric is assessed by energy absorption (EA). It is assumed to be same as the loss of kinetic energy of the projectile. Energy absorption in fabric can be calculated according to Equation (1). Due to variability of the exiting velocity of the projectile, energy absorption of a perforated panel is determined by ten shots [7].

$$
\Delta E=1 / 2 \mathrm{~m}\left(v_{\mathrm{s}}^{2}-v_{\mathrm{r}}^{2}\right)
$$

where $\Delta E$ is the energy absorption by the panel $(\mathrm{J}), m$ is the mass of the projectile $(\mathrm{kg}), v_{\mathrm{s}}$ and $v_{\mathrm{r}}$ are the impact velocity and the residual velocity respectively $(\mathrm{m} / \mathrm{s})$. 


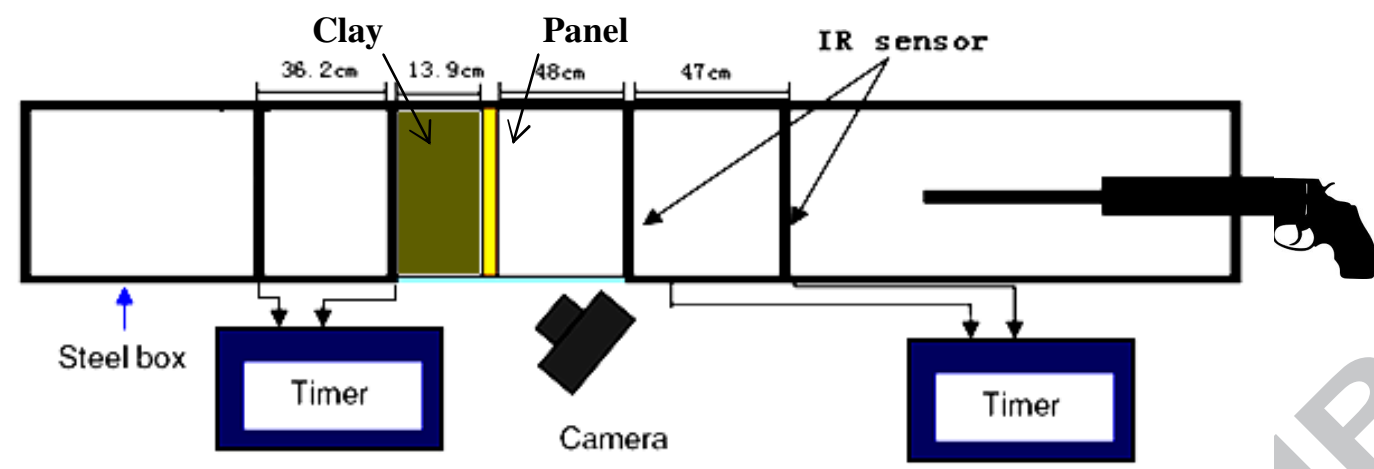

(a)

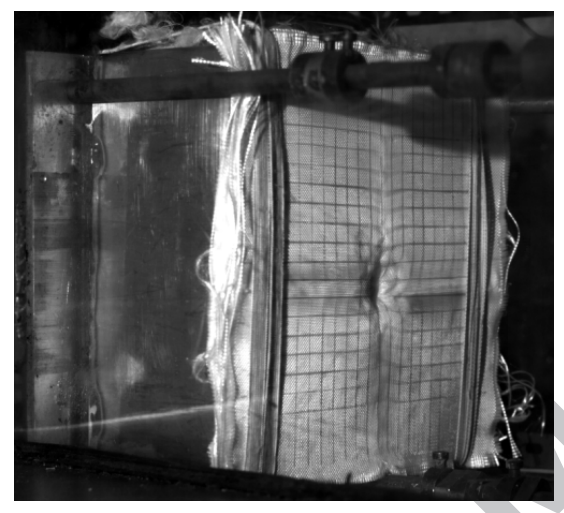

(b) Frame

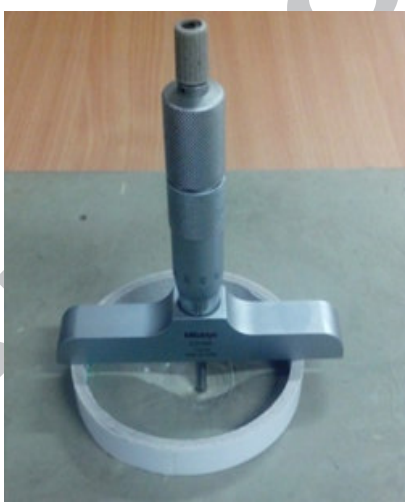

(c) Clay

Figure 2 Ballistic test set-up

\section{Results and discussions}

\subsection{Validation of FE model}

When a single layer of fabric is impacted by a projectile with the velocity of $483 \mathrm{~m} / \mathrm{s}$, the fabric is perforated. Figure 3 shows the impact process in FE modelling and ballistic test. According to observation of the impact process by a high speed camera, the maximum transverse deformation area in fabric at $5.5 \mu \mathrm{s}$ exhibits about $10 \mathrm{~mm}$ of the width. For the FE model, the maximum width of transverse deformation area at $5.5 \mu \mathrm{s}$ is $12.6 \mathrm{~mm}$, which is close to test results. 


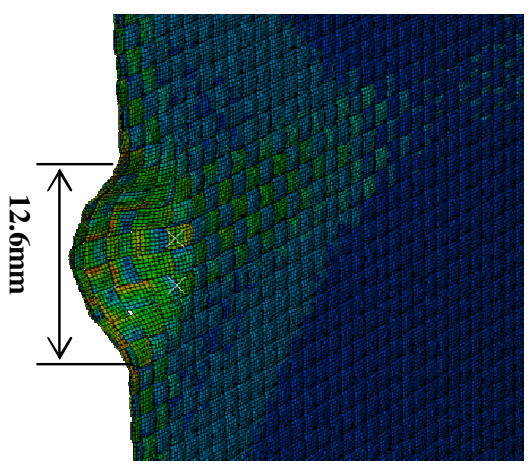

(a) FE modelling

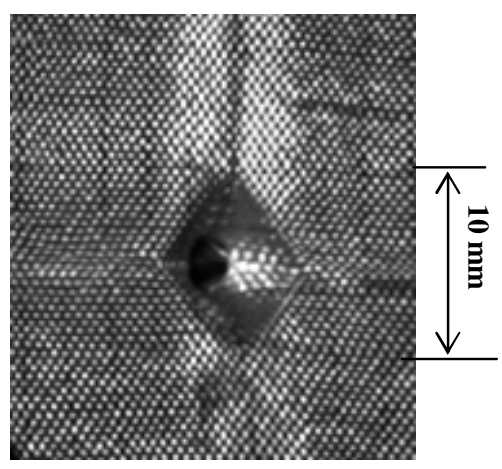

(b) Ballistic test

Figure 3 Transverse deformation of Twaron fabric $11 \mathrm{~F}$ at $5.5 \mu$ s under ballistic impact:

(a) FE modelling; (b) Ballistic test

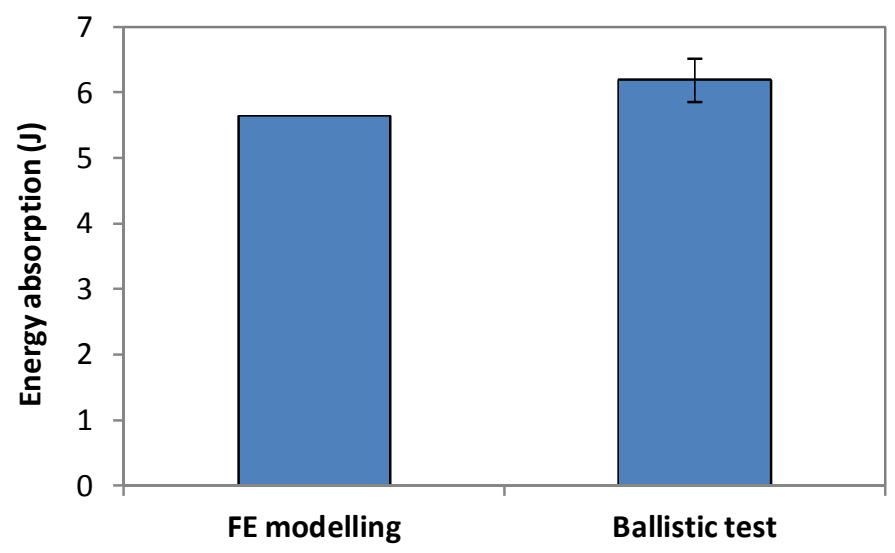

Figure 4 Energy absorption of Twaron fabric $11 F$

Energy absorption in fabric is one of the most vital validation criteria for FE modelling in the perforation case. According to FE results, energy absorption of an individual layer fabric is $5.65 \mathrm{~J}$, which shows a good agreement with test results of $6.19 \mathrm{~J}$, as shown in Figure 4. The little difference can be explained that the friction between fibres cannot be taken account in FE model at the yarn level. This results in less friction energy absorption in FE model of fabric.

In the non-perforation case, the projectile is stopped in the panel $11 \mathrm{~F}_{24}$ and front seven layers are perforated in FE model as shown in Figure 5 (a). This is the same as the ballistic test result. After impact, an indentation is left in clay, as shown in Figure 5 (b). In the 
FE model, a round indentation displays the depth of $8 \mathrm{~mm}$, and the width of $44 \mathrm{~mm}$, which is similar as that of ballistic test result, as shown in Figure 5 (c) and (d).

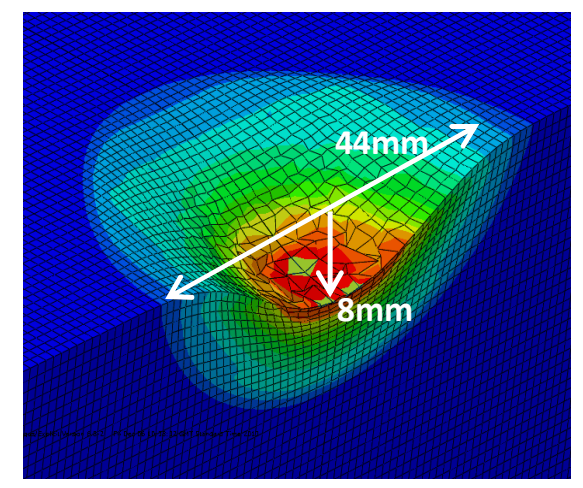

(a)

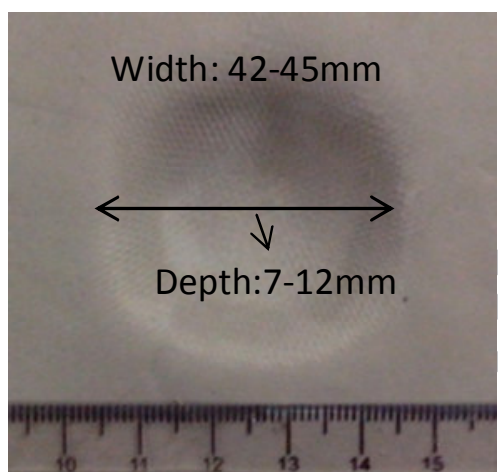

(b)

Figure 5 FE result and test result of the clay behind the Twaron panel $\mathbf{1 1 F}_{24}$

According to above analysis, FE simulation results can represent ballistic characteristics of Twaron fabric and multilayer panel very well, including energy absorption, transverse deflection and BFS. These results indicated that FE models of an individual fabric and multilayer armour panels are both valid. They can be used to analyse ballistic response characteristics of soft armour panels.

\subsection{Energy absorption distribution in armour panel}

When an armour panel is impacted by a projectile at high impact velocity, the impact energy of the projectile is mainly converted into the kinetic energy, strain energy and the frictional energy in fabric [24, 25] [26]. In these three forms, frictional energy accounts for small proportion [27] [28]. For the same fabric material and weave structure of each layer, the difference of frictional energy between layers is not significant. Therefore, only kinetic energy and strain energy are investigated to represent difference of energy absorption in each layer. 
Under transverse impact, each fabric layers in the panel is under high stress. The yarns are stretched and fabric produces transverse deformation until the fracture moment for those perforated layers. Therefore, the maximum energy absorption of perforated layers in FE results is corresponded to the fracture moment. However, the projectile won't stop at once until all kinetic energy is dissipated. This results in yarn pull-out, yarn bowing, transverse deformation of fabric and other failure mechanisms. Therefore, for those non-perforated layers, the maximum energy absorption in FE results is corresponded to the stop moment of the projectile.

Figure 6 shows energy absorption of each layer in the panel $11 \mathrm{~F}_{24}$. The last perforated layer (the $7^{\text {th }}$ layer) has the highest energy absorption among all layers. Whereas for the front few layers (the front three layers) and some back layers (the back ten layers), energy absorption is much lower. On the whole, energy absorption by each layer is increased from the front layer to the maximum value by the last perforated layer and then decreased gradually in the following back layers.

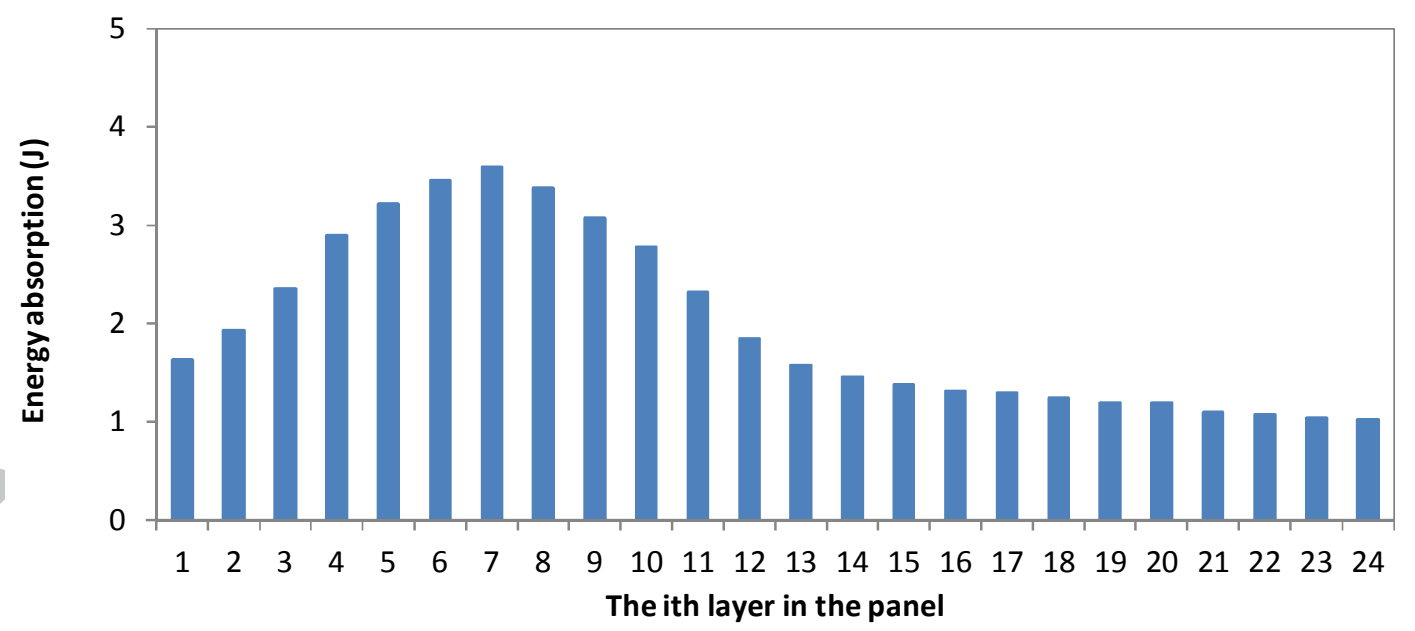

Figure 6 Energy absorption of each layer in Twaron woven panel $\mathbf{1 1 F}_{24}$ at the striking velocity of $483 \mathrm{~m} / \mathrm{s}$ 
According to our previous studies [10], for this given impact condition, this pattern of energy absorption distribution remains the same regardless of increasing total number of layers in the panel. The last perforated layer always has the highest energy absorption among layers in a panel. The position of the last perforated layer can be identified in certain region of a panel for a given material and threat level. Because the amount of fabric material required dissipating a certain amount of kinetic energy of a projectile by fracture is constant.

\subsection{Energy absorption efficiency of each layer}

According to above results, energy absorption has a different extent of decrease in comparison with that of an individual layer. In order to quantify the contribution of each layer in energy absorption when combining in a panel, energy absorption efficiency $\mathrm{R}$ is adopted in this study according to

$$
R=\frac{E A_{i t h}}{E A_{S}} \times 100 \%
$$

where $R$ is the energy absorption efficiency, $E A_{i t h}$ is the energy absorption of the $\mathrm{i}^{\text {th }}$ layer in a panel, and $E A_{s}$ is the energy absorption of an individual fabric layer.

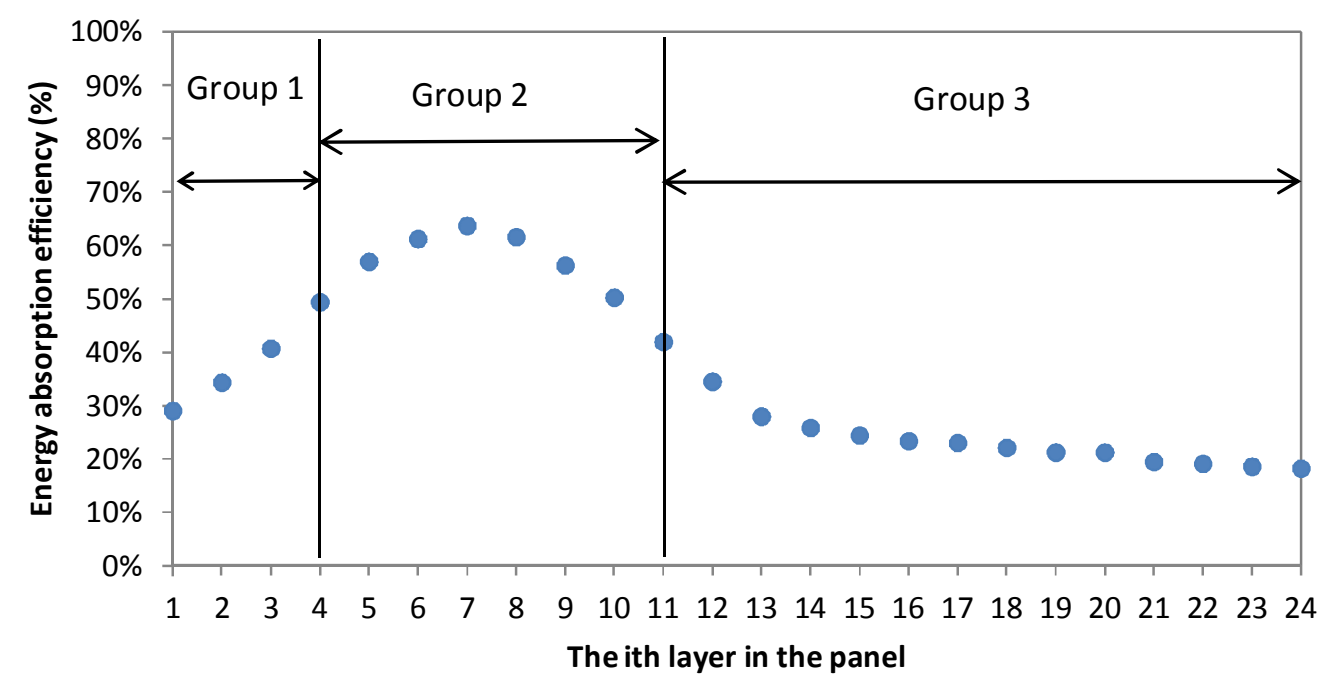

Figure 7 Energy absorption efficiency of Twaron woven panel $\mathbf{1 1 F}_{24}$ 
Energy absorption of an individual fabric is used as the reference baseline according to FE results. It represents the maximum energy absorption capacity of Twaron fabric during ballistic impact at free condition without any boundary constraint. Energy absorption efficiency $\mathrm{R}=100 \%$ means that the fabric layer in the panel is as effective as the individual layer in energy absorption. Whereas $\mathrm{R}<100 \%$ indicates that the energy absorption of the fabric layer in the panel is constrained. In a case where $\mathrm{R}>100 \%$, it implies that the same fabric is more efficient in energy absorption.

Figure 7 shows the energy absorption efficiency of each fabric layer in the panel $11 \mathrm{~F}_{24}$. The energy absorption efficiency of all layers in the panel $11 \mathrm{~F}_{24}$ is less than $100 \%$. The last perforated layer (the seventh layer) has the highest energy absorption efficiency of only $61.3 \%$ in the panel. It is. While the energy absorption efficiency of the front three layers and some back layers (ply-11 to ply-24) is less than 50\%. This indicates that energy absorption of all layers is constrained. This can be explained that due to the constraint by back clay, all fabric layers in the panel can't produce the transverse deformation freely as that of the individual fabric layer. In comparison with the energy absorption efficiency of the front and back layers, those middle layers close to the last perforated layers play the dominant role of energy absorption in an armour panel.

\subsection{Group division in a multilayer panel}

According to the energy absorption efficiency, each fabric layer in an armour panel plays different roles in ballistic resistance. Therefore, combining same fabric layers in an armour panel cannot be the most efficient construction for ballistic protection. To optimise the construction of an armour panel, different materials can be combined at different positions, which is the hybrid armour panel. The key issue of designing hybrid panel is to identify different requirements at different positions in a panel for proper ballistic materials selection. 


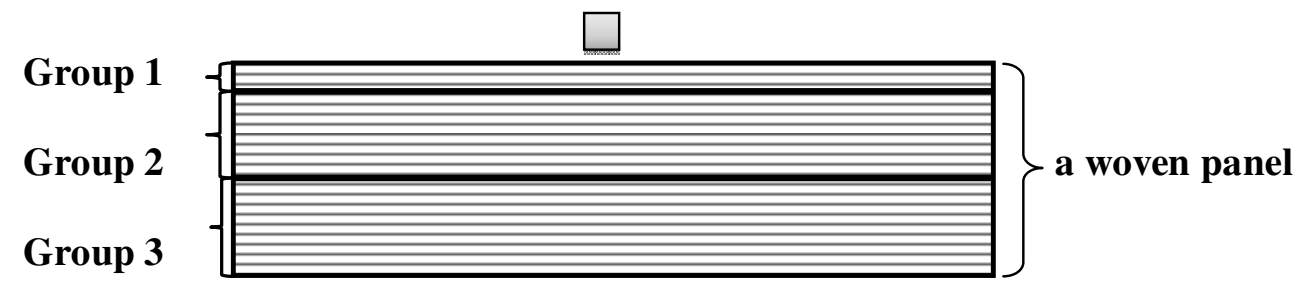

Figure 8 Schematic of a panel division

Based on energy absorption efficiency of each layer, the reference panel $11 \mathrm{~F}_{24}$ can be divided into three groups, as shown in Figure 8. Front three layers which have lower energy absorption efficiency below $50 \%$ are classified into the first group. The layers close to the last broken layer from the fourth to the tenth layer which have relatively higher energy absorption efficiency above $50 \%$ are classified into second layer. The third group includes all back layers from the $11^{\mathrm{h}}$ to $24^{\text {th }}$ which has less than $50 \%$ of energy absorption efficiency. The schematic of a panel division is shown in Figure 8.

It needs to be mentioned that such group division of this panel is specified for the impact condition in this study. When the threat level is improving, such as increasing of the impact velocity, the pattern of energy absorption distribution in a panel will be changed. This has already been investigated in detail through FE modelling in one our previous paper [10]. As a result, the group division will be varied according to the pattern of energy absorption distribution in a panel under higher threat level. In addition, for a given fabric material, although the weave structure can also have influences on the number of layers in each group, the pattern of energy absorption distribution in a panel cannot be changed for a given impact energy [12]. Therefore, for different weave structures of fabric layer with the same material, only the number of layers in each group is varied.

According to FE results and experimental results, fabric layers in three groups exhibit different characteristics of ballistic responses under impact. 


\subsubsection{The first group}

When a projectile impacts on a panel, the stress waves are generated from the impact point and propagated down the axis of the primary yarns. The transverse deflection is produced in primary yarns of each layer. Figure 9 shows Mises stress contours along the primary yarn before fracture in some layers from three different groups. This represents stress distribution characteristics of layers in each group before fracture.

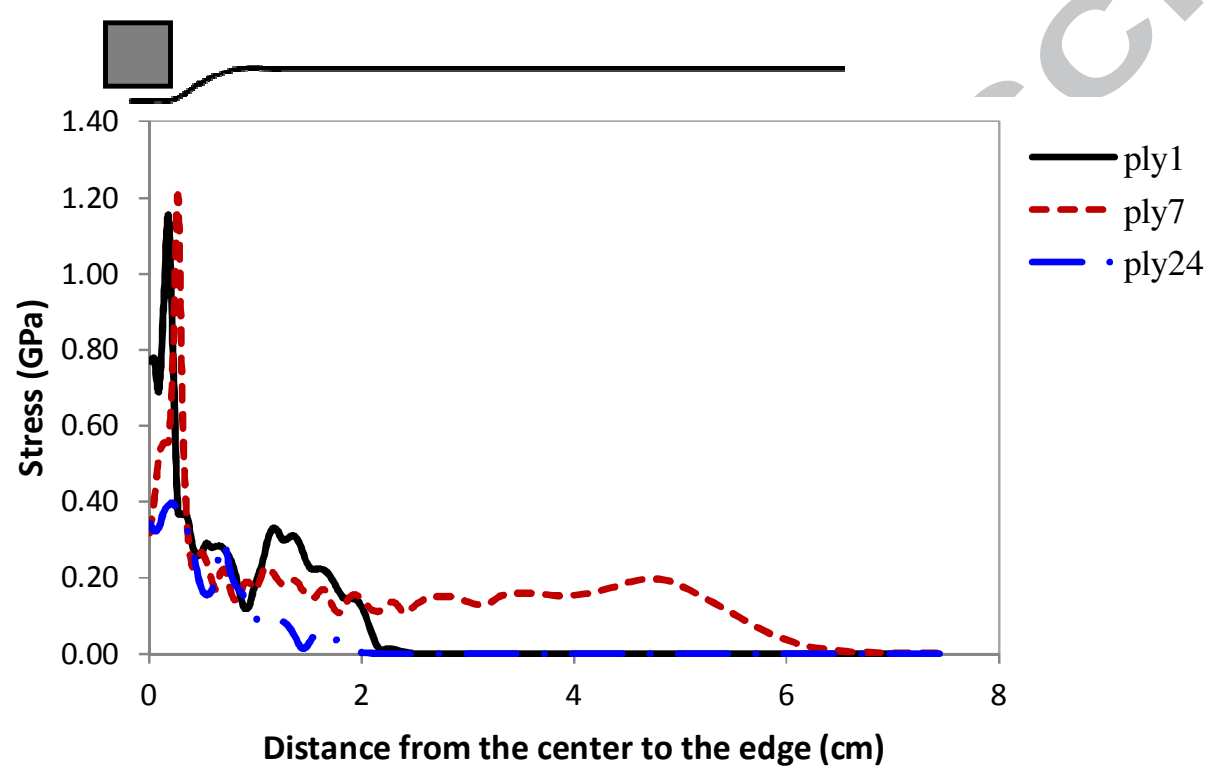

Figure 9 FE results of stress distribution in $\mathrm{Twaron}_{\text {panel }} \mathbf{1 1 F}_{24}$ under impact

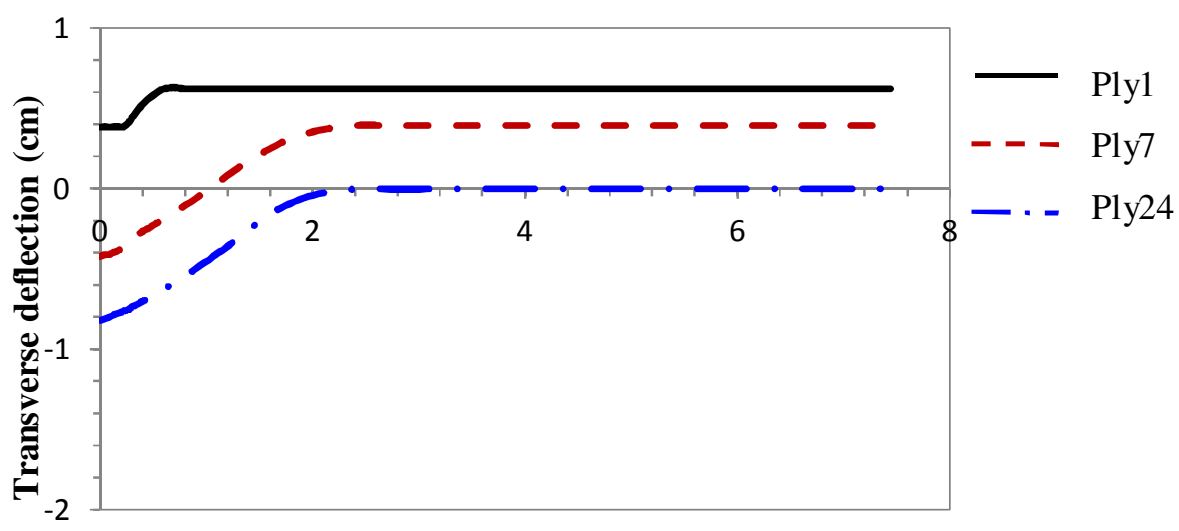

Distance from the center $(\mathbf{c m})$

Figure $10 \mathrm{FE}$ results of transverse deflection in Twaron panel $\mathbf{1 1 F}_{24}$ under impact 

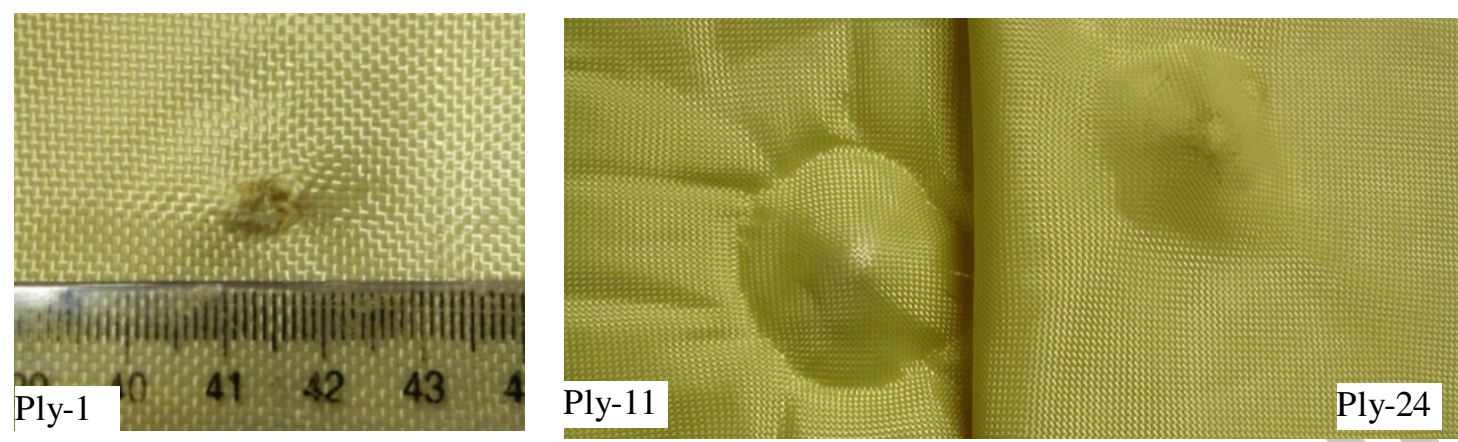

Figure 11 Transverse deformation of fabric layers in post-impact panel $\mathbf{1 1 F}_{\mathbf{2 4}}$

Figure 10 shows deflection profiles of a primary yarn in some layers in three groups at different time during impact according to $\mathrm{FE}$ results. As the transverse deflection is proportion to the transverse deformation area of fabric layer, this represents the maximum extent of transverse deformation of each layer in a panel. The maximum transverse deflection of perforated layers is corresponding to the fracture moment of this layer. For the nonperforated layers, the maximum transverse deflection is corresponding to the stop moment of the projectile.

Taking the front layer (ply1) on the striking face as an example for the first group, high stress concentration is found in the contact area around the edge of the projectile. The stress on the primary yarn is increased sharply during less than $10 \mu \mathrm{s}$. Due to the fabric layer failed very quickly, the stress wave cannot propagate widely. In addition, the transverse deformation area of three layers in the first group is only localised around the edge of the projectile. The transverse deflection is less obvious. This can be also observed from the post-impact panel as shown in Figure 11. Such ballistic characteristics of the first group indicate that some tough materials should be combined on the striking face in order to sustain longer before fracture under impact.

\subsubsection{The second group}


The second group contains fabric layers close to the last perforated layer (ply4-ply10). The last perforated layer (ply7) is taken as an example for this group. FE results shows that the fabric layer has longer interaction time (around $20 \mu \mathrm{s}$ ) with the projectile before fabric fracture than that of front layers. The stress wave can propagate over wider area from the impact point to the edge of fabric before fabric fracture, as shown in Figure 9.

Correspondingly, the transverse deformation area in the fabric layer becomes even wider, as shown in Figure 10. This can also be observed from the post-impact panel after ballistic test as shown in Figure 12. The middle layer in the second group has an obvious transverse deformation area than that of the front layer (ply-1) in the first group and the last layer (ply-24) in the third group. As a result, more fabric material of each layer in this group can be engaged in energy absorption. This means that these layers at such positions can make best use of fabric materials. The influence of weave structure of fabric on energy absorption capacity has been investigated in detail in our previous studies [12]. It is found that the lightweight fabrics can be combined in this group to apply higher energy absorption capacity. The lightweight fabric can be obtained by using fine yarns or reducing the weave density.

\subsubsection{The third group}

The back layers in the third group cannot be perforated and only produce transverse deformation until the projectile stop. Due to attenuated impact force, the stress magnitude becomes lower, as shown in Figure 9. The transverse deflection is gradually decreased, as shown in Figure 10 and 11. As a result, materials properties in back layers cannot be fully applied during ballistic impact process. This results in low energy absorption efficiency of fabric layers in this group.

However, these layers in the back group play important roles in minimizing BFS of the panel according to ballistic tests, as shown in Figure 12. In comparison with the panel 
$11 \mathrm{~F}_{24}$, BFS behind the panel $11 \mathrm{~F}_{36}$ and $11 \mathrm{~F}_{48}$ decreases $11.2 \%$ and $25.92 \%$ respectively. With more layers added in the non-perforated panel, BFS behind panels decreases more significantly. It can be inferred that when a panel is added by numerous fabric layers, there would be no indentation in clay, due to little transmitted energy through the panel. Therefore, the material which possesses high stress wave velocity resulting in lower BFS should be combined in this group.

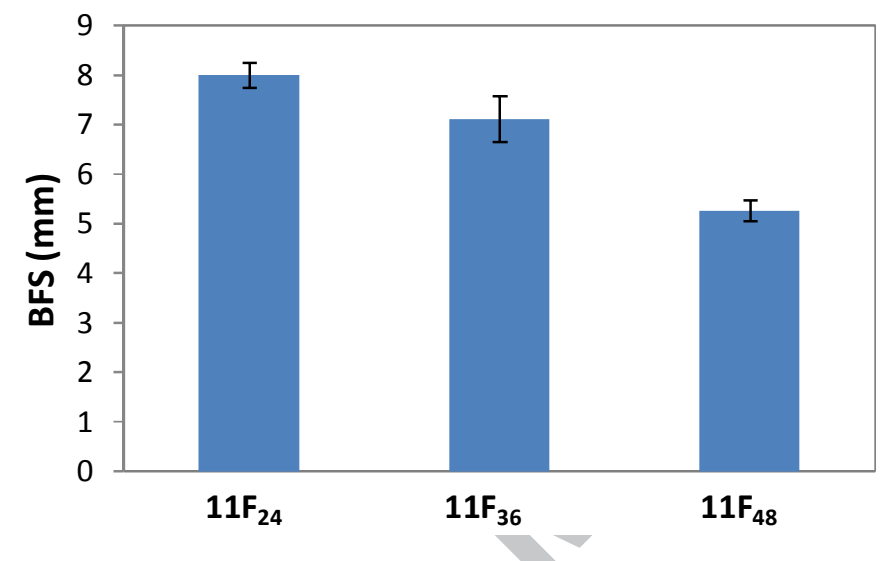

Figure 12. Backface signature (BFS) of Twaron panels

\section{Hybrid design}

According to above design principle, the construction of the panel $11 \mathrm{~F}_{24}$ is optimised by combining different components. Three layers of Twaron fabrics $13 \mathrm{~F}$ with higher weave density are placed at the first group. Due to increasing amount of materials at unit area, the fabric $13 \mathrm{~F}$ has higher absolute value of energy absorption than that of $11 \mathrm{~F}$. This results in increasing higher ballistic resistance capacity of front group under impact. For the second group, seven layers of fabrics $11 \mathrm{~F}$ are still used according to the panel division. Due to typical structures, Dyneema UD laminates possess high stress wave velocity, which results in low BFS. Therefore, Dyneema UD layers are combined at the back group to constrain BFS of a panel. The total number of UD layers is determined by the required areal density. Two 
hybrid panels are designed, namely $13 \mathrm{~F}_{3} / 11 \mathrm{~F}_{7} / \mathrm{U}_{14}$ and $13 \mathrm{~F}_{3} / 11 \mathrm{~F}_{7} / \mathrm{U}_{5}$. The non-perforation and perforation ballistic tests were conducted to identify ballistic performance.

The hybrid panel $13 \mathrm{~F}_{3} / 11 \mathrm{~F}_{7} / \mathrm{U}_{14}$ was conducted non-perforation tests and successfully stopped every shot. In comparison with the reference panel $11 \mathrm{~F}_{24}$, the average BFS of the hybrid panel decreases $31.54 \%$ at almost the same areal density, as shown in Table 4 . This result indicates that ballistic resistance capacity of the hybrid panel is greatly improved without increasing the areal weight.

For the hybrid panel $13 \mathrm{~F}_{3} / 11 \mathrm{~F}_{7} / \mathrm{U}_{5}$, at the average impact velocity of $487.24 \mathrm{~m} / \mathrm{s}$ in six shots, three panels were perforated and other three panels were not perforated. Referred to V50 test [21], this can be regarded as $50 \%$ probability of perforation for the given impact condition. With the same areal density, the woven panel $11 \mathrm{~F}_{15}$ with eleven layers cannot stop any shot for the same impact condition. This indicates that the hybrid panel is more likely to stop the projectile in comparison with that of the fabric panel when the areal weight of panel is reduced.

Table 4 Ballistic test results of hybrid panels and woven panels

\begin{tabular}{|c|c|c|c|c|c|c|c|}
\hline Hybrid panel & $\begin{array}{c}\text { Areal } \\
\text { density } \\
\left(\mathrm{g} / \mathrm{m}^{2}\right)\end{array}$ & $\begin{array}{c}\text { Impact } \\
\text { velocity } \\
(\mathrm{m} / \mathrm{s})\end{array}$ & $\begin{array}{c}\text { Ave Impact } \\
\text { velocity } \\
(\mathrm{m} / \mathrm{s})\end{array}$ & Status & $\begin{array}{c}\text { BFS } \\
(\mathrm{mm})\end{array}$ & $\begin{array}{l}\text { Ave } \\
\text { BFS } \\
(\mathrm{mm}) \\
\end{array}$ & STD \\
\hline \multirow{3}{*}{$11 F_{24}$} & \multirow{3}{*}{4724.4} & 485.04 & \multirow{3}{*}{480.4} & $\begin{array}{c}\text { Non- } \\
\text { Perforated }\end{array}$ & 15.75 & \multirow{3}{*}{15.25} & \multirow{3}{*}{1.12} \\
\hline & & 473.65 & & $\begin{array}{c}\text { Non- } \\
\text { Perforated }\end{array}$ & 13.57 & & \\
\hline & & 482.53 & & $\begin{array}{c}\text { Non- } \\
\text { Perforated }\end{array}$ & 14.22 & & \\
\hline \multirow{3}{*}{$13 \mathrm{~F}_{3} / 11 \mathrm{~F}_{7} / \mathrm{U}_{14}$} & \multirow{3}{*}{4750.39} & 490.25 & \multirow{3}{*}{488.13} & $\begin{array}{c}\text { Non- } \\
\text { Perforated }\end{array}$ & 10.04 & \multirow{3}{*}{10.44} & \multirow{3}{*}{0.87} \\
\hline & & 487.36 & & $\begin{array}{c}\text { Non- } \\
\text { Perforated }\end{array}$ & 11.44 & & \\
\hline & & 486.79 & & $\begin{array}{c}\text { Non- } \\
\text { Perforated }\end{array}$ & 9.85 & & \\
\hline \multirow{4}{*}{$11 \mathrm{~F}_{15}$} & \multirow{4}{*}{2952.75} & 485.04 & \multirow{4}{*}{483.02} & Perforated & I & I & I \\
\hline & & 481.56 & & Perforated & I & I & I \\
\hline & & 481.06 & & Perforated & I & I & I \\
\hline & & 483.75 & & Perforated & l & l & l \\
\hline
\end{tabular}




\begin{tabular}{|c|c|c|c|c|c|c|c|}
\hline & & 487.29 & & Perforated & I & I & I \\
\hline & & 479.41 & & Perforated & I & 1 & I \\
\hline \multirow{6}{*}{$13 \mathrm{~F}_{3} / 11 \mathrm{~F}_{7} / \mathrm{U}_{5}$} & \multirow{6}{*}{3067.93} & 490.70 & \multirow{6}{*}{487.24} & Perforated & 1 & 1 & 1 \\
\hline & & 487.52 & & Perforated & 1 & 1 & 1 \\
\hline & & 488.25 & & Perforated & 1 & I & I \\
\hline & & 481.56 & & $\begin{array}{c}\text { Non- } \\
\text { Perforated }\end{array}$ & 16.33 & \multirow{3}{*}{15.81} & \multirow{3}{*}{0.6} \\
\hline & & 489.66 & & $\begin{array}{c}\text { Non- } \\
\text { Perforated }\end{array}$ & 15.14 & & \\
\hline & & 485.75 & & $\begin{array}{c}\text { Non- } \\
\text { Perforated }\end{array}$ & 15.96 & & \\
\hline
\end{tabular}

\section{Conclusions}

In this study, energy absorption efficiency in soft armour panel under ballistic impact was investigated through FE simulation and experimental tests. It is found that all fabric layers possess lower energy absorption efficiency in comparison with that of an individual layer. In particularly, energy absorption efficiency of some layers at front and back of the panel is less than $50 \%$.

According to energy absorption efficiency of each layer, the panel $11 \mathrm{~F}_{24}$ is divided into three groups. Front three layers are classified into the first group. The second group includes some middle layers close to the last perforated layer. All back layers are classified into the last group. Fabric layers in these three groups exhibit different ballistic characteristics of transverse deformation and stress distribution. Therefore, different ballistic requirements for material selection are identified at different positions of armour panel.

Based on these design principle, two hybrid panels that was combining different Twaron fabrics and Dyeema UD laminates were designed. The ballistic tests confirm the positive effect in ballistic performance. For a given areal density of the panel, BFS behind the hybrid panel decreases $31.54 \%$ than that of the woven fabric panel. When the areal density of 
armour panel is reduced, the hybrid panel has more probability to stop the projectile. These results provide a good guide for the design of ballistic armour panel.

\section{Acknowledgments}

This work is financially supported by Key Scientific Research Projects of High Education of Henan No.16A540007 and Research Fund for key laboratory of Technical Textile in Henan No.4600-32010017.

\section{Reference:}

[1] Azrin Hani AR, Roslan A, Mariatti J, Maziah M. Body Armor Technology: A Review of Materials, Construction Techniques and Enhancement of Ballistic Energy Absorption. Adv Mater Res. 2012;488489:806-12.

[2] Cavallaro PV. Soft Body Armor: An Overview of Materials, Manufacturing, Testing, and Ballistic Impact Dynamics. NUWC-NPT Technical Report 12,057. Newport, Rhode Island: Naval Undersea Warfare Center Division; 2011.

[3] Bajaj P, Sriram. Ballistic protective clothing: An overview. J Fibre \&Textile res. 1997;22:274-91.

[4] Joo K, Kang TJ. Numerical Analysis of Energy Absorption Mechanism in Multi-ply Fabric Impacts. Textile Res J. 2008;78:561.

[5] Yi Zhou, Xiaozhou Gong, Shangyong Zhang, Anchang Xu. A numerical investigation into the influence of layer space on panel ballistic performance. Fibers and Polymers. 2015; 16:2663-9.

[6] Cunniff PM. Decoupled response of textile body. Proceedings of the 18th International Symposium on Ballistics. San Antonio, Texas, US1999.

[7] Karahan M, Kus A, Eren R. An Investigation into Ballistic Performance and Energy Absorbtion Capabilities of Woven Aramid Fabrics. J Impact Eng. 2008; 35(6):499-510.

[8] Prosser RA. Penetration of Nylon Ballistic Panels by Fragment-Simulating Projectiles Part I: A Linear Approximation to tlic Relationship between the Square of the V50 or Vc Striking Velocity and the Number of Layers of Cloth in the Ballistic Panel. Textile Res J. 1988;2:61-85.

[9] Chen X, Zhu F, Wells G. An analytical model for ballistic impact on textile based body armour. Composites: Part B. 2013;45:1508-14.

[10] Yang $Y$, Chen X. Investigation of energy absorption mechanisms in a soft armor panel under ballistic impact. Textile Res J. 2016;0(00) 1-12.

[11] Yang $Y$, Chen X. Study of energy absorption and failure modes of constituent layers in body armour panels. Compos Part B. 2016: 250-9.

[12] Yang Y. Study on Ballistic Performance of Hybrid Soft Body Armour. PhD thesis. University of Manchester, 2015.

[13] Chabba S, Vanek D, Cordova D. Multilayerd material sheet for use in soft ballistics. US2010.

[14] Zufle TT. Soft body armor. United States 1993.

[15] Heinecke J. From fibre to armor. Law Enforcement Technology magazine2007.

[16] Karahan M. Comparison of Ballistic Performance and Energy Absorption Capabilities of Woven and Unidirectional Aramid Fabrics. Textile Res J. 2008;78:718. 
[17] Cunniff PM. An analysis of the system effects in woven fabrics under ballistic impact. Textile Res J. 1992;62:495-509.

[18] Porwal PK, Phoenix SL. Effects of layer stacking order on the V50 velocity of a two-layered hybrid armor system. J Mech Mater Struct. 2008;3:627-39.

[19] Park JL, Chi Y-S, Kang TJ. Ballistic performance of hybrid panels composed of unidirectional/woven fabrics. Textile Tes J. 2012;0(00):1-16.

[20] Rahman M, Morozov EV, Shankar K, Fien A. Computational Analysis of Low Velocity Impact Response of Composite Panels. Appl Mech Mater. 2012;157:1135-8.

[21] U.S. Department of Justice OoJP, National Institute of Justice. Ballistic Resistance of Body Armor NIJ Standard-0101.06. Washington: National Institute of Justice; 2008.

[22] Rao MP, Duan Y, Keefe M, Powers BM, Bogetti TA. Modeling the effects of yarn material properties and friction on the ballistic impact of a plain-weave fabric. Compos Struct. 2009:556-66.

[23] Pamukcu S, Naito C, Pervizpour M, Cui Q, Trasborg PA, Medina C, et al. Distributed Fiber-Optic Sensing and Numerical Simulation of Shock Wave Response of Manufactured Clay. Aberdeen Proving Ground, MD:U.S. Army Research Laboratory; 2013.

[24] Lim CT, Shim VPW, Ng YH. Finite-element modeling of the ballistic impact of fabric armor. Int J Imact Eng. 2003;28:13-31.

[25] Lamothe D. Corps to field two new body armour vests. Marine Corps Times (Gannett)2009. p. 19.

[26] Wang $Y$, Chen X, Young R, Kinloch I. A numerical and experimental study of the influence of crimp on ballistic performance of single layer woven fabrics. Compos Struct. 2016;140:44-52.

[27] Duan $Y$, Keefe M, Bogetti TA, Cheeseman BA. Modeling friction effects on the ballistic impact behavior of a single-ply high-strength fabric. Int J Imact Eng. 2005;31:996-1012.

[28] Wang Y, Chen X, Young R, Kinloch I. Finite element analysis of effect of inter-yarn friction on ballistic impact response of woven fabrics. Compos Struct. 2015;135:8-16. 